Over a year this has developed into a comprehensive but easily accessible practice guide that staff know is easily available on their desktops and in paper format in a ward folder. As new policies are updated a 'quick reference' guide is created and added to the resource.

This change has been supported by education as each topic is added so all staff are aware of changes to clinical practice and how to access the most up to date information.

\section{P-246 NEW METHOD FOR CLINICAL RISK MANAGEMENT}

Jayne Dingemans, Sarah Bell, Steve Mellish, Susan Plummer. Garden House Hospice Care, Letchworth Garden City, UK

\subsection{6/bmjspcare-2017-hospice.271}

Background We recently reviewed and revised our methodology for risk management. The existing process was not intuitive or informative; did not demonstrate the seriousness of some risks or how much work had been invested in mitigating them. Critically, risks faced and the levels at which they were being managed were not well understood or appreciated by the Board of Trustees.

Aim To revise the methodology and format for recording clinical risks and controls, so allowing an improved understanding of the risks and enhance clarity around existing controls. To augment identification of areas where controls require enhancement and record the actions taken to allow this.

Method After agreeing the new format for the risk register and risk presentation, all existing risks were reviewed. This produced a clearer understanding of the new terms of 'gross risk', defining the level of risk with no controls in place and 'net risk', defining the level of risk with mitigation actions in place. The register additionally documented the controls in place to mitigate risks and the probability and potential impact of each risk.

Results Key risks were accurately and clearly highlighted, based on causes and consequences, to both the clinical team and Board of Trustees. This resulted in a better understanding of organisational risk appetite. The effect of existing controls was clearly evidenced and areas where further controls were required was demonstrated.

Conclusion This process has significantly enhanced our understanding of the risks faced by the hospice clinical team, clarified the work already undertaken to mitigate risks and identified areas where further controls are required. Improving our risk management process has put us in a better position to justify future investments. As a consequence of success with this new clinical risk management approach, all other institutional risks registers are to be put into this format.

\section{P-247 HOW CAN FUNDRAISERS FUNDRAISE EFFECTIVELY IF THEY DON'T KNOW WHAT WE DO?}

Sarah Wells, Lyn Wood. Marie Curie Hospice West Midland, Solihull, UK

\subsection{6/bmispcare-2017-hospice.272}

Background Fundraisers are key to the livelihood of our hospices. Their voice within the community represents the work that we do and the patients that we care for. The fundraising team at our hospice have become actively involved in Schwartz rounds, both as panellists and audience members. As a facilitator responsible for preparing panellists, it became apparent that the fundraisers did not have a clear idea of the work that the clinicians were involved in.

Methods Following discussion with the Fundraising manager, a programme of immersion in clinical activities for the fundraising team was planned. This included attending the in-patient unit and day services during the induction period as well as established fundraisers attending ward rounds and day services to understand the complex care that is being delivered by our staff.

Results $90 \%$ of the fundraising team have now attended a ward round. The result has been incredibly positive:

- They have felt enlightened on the extent of care being delivered

- They feel more connected with the clinical team

- Increased connexion with patients

- It has been very emotional and at times difficult for them but still wholeheartedly welcomed

- They feel that they are able to give a much clearer and emotive description of the care we are providing while out in the community.

- We plan to continue this programme and extend to attending day services.

\section{P-248 CARE TOWARDS THE END OF LIFE COURSE FOR CARERS 'HOW PEOPLE DIE REMAINS IN THE MEMORY OF THOSE WHO LIVE ON', DAME CICELY SAUNDERS}

Claire Hewitt, Sharon Kelly. The Hospice of St Francis, Berkhamsted, UK

\subsection{6/bmjspcare-2017-hospice.273}

Background It has been evidenced 'By improving communication about the medical, practical, psychosocial, and religious/ spiritual issues that surround death and dying will lead to caregivers being better prepared for the death and, as a result, improve their well-being' Herbert RS et al. (2009). Locally from completing the Carer Support Needs Assessment Tool (CSNAT) (Ewing \& Grande, 2013), we are finding that the most common domain identified by carers and needing additional support is 'knowing what to expect in the future.' Therefore, in collaboration with carers in Hertfordshire and the Peace Hospice in 2013 the 'Care towards the End of Life Course for Carers' was developed to be run across both hospices.

The Aim of the Course To provide a safe forum to educate carers and provide support for those in a similar positon. To share experiences and build on their confidence, particularly in having difficult conversations.

Methods A six-week programme is delivered twice a year covering a range of relevant topics, each one developed further from feedback. We aim to have 12 people attend.

Results Forty-nine carers have attended the courses. 92\% of carers were very satisfied with the content and delivery. Carers' feedback: 'The knowledge of understanding of what's to come'; 'That it is never too early but can be too late'; 'Reaffirmed that I am doing the right things and planning correctly.'

Conclusions The impact of the carer journey can significantly influence the bereavement process. The feedback supports the need of the course in providing information and support to carers who are who are caring for a person who is approaching their end of life. We have been contacted by other 